\title{
Effect of carbonaceous aerosols on surface temperature in the mid twentieth century
}

\author{
Tatsuya Nagashima, ${ }^{1}$ Hideo Shiogama, ${ }^{1}$ Tokuta Yokohata, ${ }^{1}$ Toshihiko Takemura, ${ }^{2}$ \\ Simon A. Crooks, ${ }^{3}$ and Toru Nozawa ${ }^{1}$ \\ Received 7 October 2005; revised 6 December 2005; accepted 12 January 2006; published 17 February 2006.
}

[1] Simulations using a climate model are used to investigate the possible impact of increasing emissions of carbonaceous aerosols on near-surface temperature in the mid-20th century. The annual global mean near-surface temperature change from the mid-20th century onward is reasonably described by a model that is forced by changes in most of the known climate forcing agents including an increase in carbonaceous aerosols, though it can also be well reproduced without increases in carbonaceous aerosols. However, if we consider spatio-temporal structure of the changes in the near-surface temperature, an increase in carbonaceous aerosols is definitely required for the model to represent changes in the near-surface temperature in the mid-century, in particular, cooling trends in the tropical and subtropical continents. The significance of an increase in carbonaceous aerosols as an indispensable contributor to mid-20th century temperature changes is confirmed with the use of an optimal fingerprinting methodology. Citation: Nagashima, T., H. Shiogama, T. Yokohata, T. Takemura, S. A. Crooks, and T. Nozawa (2006), Effect of carbonaceous aerosols on surface temperature in the mid twentieth century, Geophys. Res. Lett., 33, L04702, doi:10.1029/2005GL024887.

\section{Introduction}

[2] The Earth's near-surface temperature in the mid 20th century, from mid 1940s to mid 1970s, shows a slight cooling, while apparent global warming has occurred in both the early and the late 20th century [Intergovernmental Panel on Climate Change (IPCC), 2001, and references therein]. The likely causes of the global warming in these periods has been the focus of several studies using state-ofthe-art coupled atmosphere-ocean models (climate models) [e.g., Delworth and Knutson, 2000; Tett et al., 2002; Meehl et al., 2004; Nozawa et al., 2005], however there is little literature which refers to the cause of the mid century cooling.

[3] Wigley et al. [1997] showed that the levelling off of solar irradiance in the mid century brought a reasonable cooling trend to their energy-balance model, whereas Andronova and Schlesinger [2000] suggested that an internal oscillation over the North Atlantic and its adjacent land

\footnotetext{
${ }^{1}$ Atmospheric Environment Division, National Institute for Environmental Studies, Ibaraki, Japan.

${ }^{2}$ Research Institute for Applied Mechanics, Kyushu University, Fukuoka, Japan.

${ }^{3}$ Department of Physics, University of Oxford, Oxford, UK.
}

area with a period of $65-70$ years is a possible explanation of the cooling in the mid century. Tett et al. [1999] proposed that the cooling effect of sulfate aerosols could balance the effect of greenhouse gases in the mid century giving a slight cooling trend. However, none have explicitly considered the impact of carbonaceous aerosols which ought to have a large impact on the near-surface temperature [e.g., Ramanathan et al., 2001].

[4] Using a climate model forced with a range of different anthropogenic aerosol emissions we investigate the impact of increasing emissions of carbonaceous aerosols on mid-20th century near-surface temperature change. A detailed comparison is made between the observed spatial and temporal temperature change over this period and the spatial and temporal responses simulated by our climate model.

\section{Model and Experiments}

[5] The climate model used in this study is MIROC3.2 [K-1 Model Developers, 2004], which has a horizontal resolution of T42 (grid spacing $2.8^{\circ}$ in both longitude and latitude) in the atmosphere and $1.4^{\circ}$ longitude by $0.5^{\circ}-1.4^{\circ}$ latitude in the ocean. The model has 20 levels in the vertical in the atmosphere and 44 levels in the ocean. This model is coupled with an aerosol transport model, SPRINTARS [Takemura et al., 2002] that can handle five kinds of aerosols (soil dust, sea-salt, sulfate, organic carbon (OC), and black carbon (BC)). SPRINTARS can explicitly deal with the first and second indirect effects that soluble aerosols change size of cloud droplet and lifetime of cloud acting as cloud condensation nuclei respectively, as well as the direct effect that aerosol particles scatter and absorb the solar and thermal radiation.

[6] We performed three experiments, spanning the years from 1850 to 2000. Each of them was forced by different combinations of historical changes in anthropogenic aerosol emissions in order to investigate the impact of such changes on 20th century climate. In the experiment labeled "SC-INCR", the carbonaceous $(\mathrm{OC}+\mathrm{BC})$ aerosols and the precursors of the sulfate aerosols $\left(\mathrm{SO}_{2}\right)$ increase according to estimations derived from country-based inventory data. The emissions of $\mathrm{SO}_{2}$ are referred from Lefohn et al. [1999], while those of carbonaceous aerosols are provided by T. Nozawa (unpublished data, 2005); a brief description of which is given by Takemura et al. [2005] and more detailed description is available at http://atm-phys.nies. go.jp/ nozawa/emission. The two other experiments were labeled 'S-INCR', where only $\mathrm{SO}_{2}$ emissions were increased, and 'SC-FIX', where both the $\mathrm{SO}_{2}$ and carbonaceous emissions were fixed at the 1850-level. In addition, 


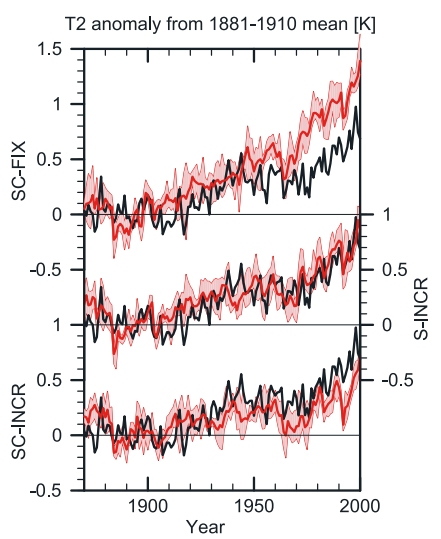

Figure 1. Time series of annual and global mean $\mathrm{T} 2$ from the observations [Jones and Moberg, 2003] (thick black lines) and from the SC-FIX, S-INCR, and SC-INCR experiments expressed as anomalies relative to the $1881-$ 1910 mean (K) (red lines). The ensemble means and the ensemble minimum-to-maximum member range (pink shade) are shown. In calculating the annual global means for the model, the model data were masked at times and locations where observational data were not available. More than ten months of data were required at each location to calculate the annual mean value.

all of the experiments were also driven by several other major external forcings relevant to the 20th century. These include historical changes in well-mixed greenhouse gases $\left(\mathrm{CO}_{2}, \mathrm{CH}_{4}, \mathrm{~N}_{2} \mathrm{O}\right.$ and halocarbons), stratospheric ozone, tropospheric ozone estimated by a chemical model, landuse, solar irradiance and stratospheric volcanic aerosol. References to the data sets of these historical changes are given by Nozawa et al. [2005]. Each experiment consists of four ensemble members, starting from different initial conditions taken from a 900 -year control simulation, at intervals of 100 years. The control simulation was performed with constant (i.e., non-time varying) external forcings which are fixed at 1850-level.

\section{Results}

[7] The evolutions of global annual mean near-surface (2m) temperatures (T2) over the 20th century derived from the three experiments were compared with observations [Jones and Moberg, 2003] in Figure 1. Until approximately 1940, the calculated warming from the end of the 19th century in each of the three experiments is similar to the observed warming during the same period. After 1940, however, SC-FIX fails to reproduce the slight cooling in the mid-century, and overestimates global warming during the late 20th century, resulting in a temperature increase at the end of the 20th century twice as large as that observed. Compared to SC-FIX, since 1940, S-INCR and SC-INCR better trace the course of observed global annual mean changes in T2. A comparison of those two experiments with SC-FIX demonstrates a significant offsetting of greenhouse-gas-induced global warming by global cooling due to increased anthropogenic aerosols. However, the better correspondence between the observed T2 change and modelled T2 change in S-INCR than in SC-INCR especially after circa 1960 could indicate that the additional cooling stemming from the carbonaceous aerosols used in the model during this period could be slightly too large.

[8] In order to take a closer look at the effect of increased carbonaceous aerosols on changes in T2 after 1940, we now examine the geographical distribution of the linear trends (trend pattern) in T2. In the latter part of the 20th century (1976-2000), both S-INCR and SC-INCR predict a significant global-mean warming, but SC-INCR catches the features of the observed trend pattern better than S-INCR (not shown). This would suggest considerable regional impacts of carbonaceous aerosols on T2 in the latter part of the 20th century as described by Menon et al. [2002] or Ramanathan et al. [2005], for example, however, the analysis of such an impact is beyond the scope of this paper and should be reported elsewhere.

[9] Around mid-century, the trend patterns from each of the three experiments differ from each other (Figure 2). Comparing the three experiments and the observations, it is clear that the trend pattern from SC-INCR gives the best agreement with the observed trend pattern, although the large-scale warming trend that occurred over Eurasia is not captured. When we measure the correspondence between the trend pattern from each experiment with the observed trend pattern using both centred- and uncentred-pattern correlation statistics [Tett et al., 1996], the values of the correlation statistics for the SC-INCR experiment are high and statistically significant, while they are low and generally insignificant for the other two experiments (see lower numbers for each experiment in Figure 2). Such is the case not only for the period shown in Figure 2 (1942-1979), but also for other periods around mid-20th century (not shown). The regional cooling trends for South China, sub-Saharan Africa, Central-South America (except Argentina) and the equatorial Atlantic coast, that are only reproduced in SC-INCR, improve the correspondence with the trend

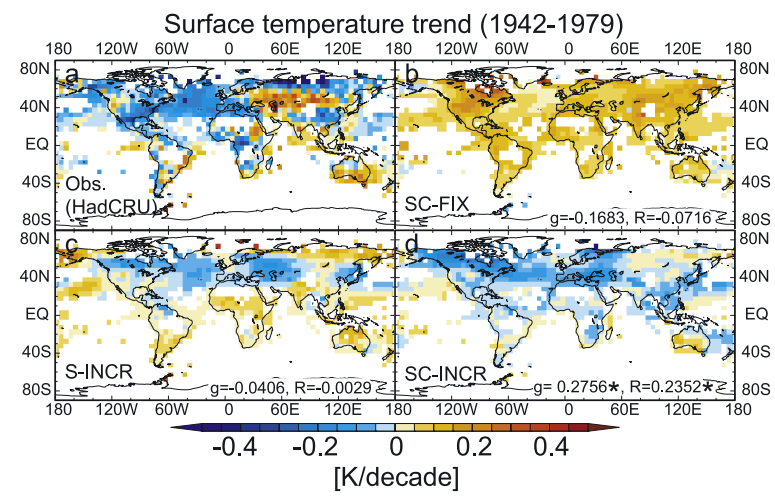

Figure 2. Geographical distributions of linear trends (K/decade) of T2 from 1942 to 1979 for (a) the observations [Jones and Moberg, 2003], (b) SC-FIX, (c) S-INCR and (d) SC-INCR. The trends were calculated from the annual mean data only for those grids where annual data is available for at least $2 / 3$ of the 38 years in question and distributed in time without significant bias. The values of the centred (R) and uncentred (g) pattern correlation statistics are shown for each experiment. An asterisk denotes that the value is outside the $\pm 2 \sigma$ range of the PDF of both statistics as estimated from the control simulation. 


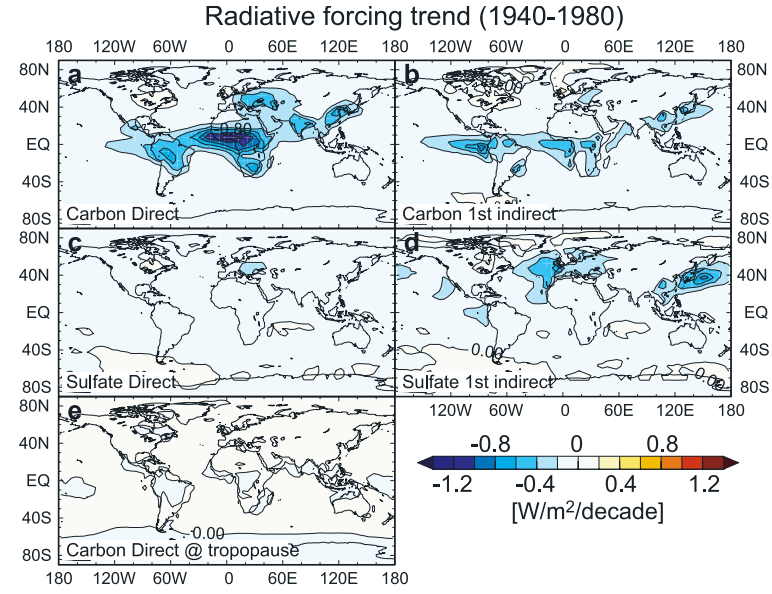

Figure 3. Geographical distributions of linear trends of net RFs from 1940 to 1980 from (a and b) carbonaceous and ( $\mathrm{c}$ and d) sulfate aerosols for direct (Figures $3 \mathrm{a}$ and $3 \mathrm{c}$ ) and first-indirect (Figures $3 \mathrm{~b}$ and $3 \mathrm{~d}$ ) effects at the Earth's surface, while Figure $3 \mathrm{~d}$ shows Figure $3 \mathrm{a}$ but at the tropopause. The linear trends were calculated using five annual mean values of RFs for 1940, 1950, 1960, 1970 and 1980.

pattern from the observations. In SC-INCR, increases in the carbonaceous aerosols loading mainly originating from biomass burning were simulated in these regions (not shown) implying that increased levels of such aerosols had a negative radiative forcing (RF) in those regions.

[10] The instantaneous RFs due to carbonaceous and sulfate aerosols were calculated separately using the atmospheric component of MIROC3.2. The RFs were calculated between 1900 and 2000 at intervals of 10 years. The estimated global annual mean net direct RFs due to BC and OC for year 2000 condition at the Earth's surface (at the top of the atmosphere) are -0.78 and $-0.36(+0.42$ and $-0.28) \mathrm{W} / \mathrm{m}^{2}$ respectively. These estimates compare well with the previous estimates [IPCC, 2001, and references therein]. The trend patterns of net RF at the surface show that the increase in both carbonaceous and sulfate aerosols invoked in SC-INCR caused cooling of most of the Earth's surface between 1940 and 1980 (Figures 3a-3d). However, the geographical distributions of radiative cooling trend caused by increases in both of these anthropogenic aerosols are completely different from each other. The above-mentioned regions, in which the cooling trend for $\mathrm{T} 2$ was only predicted by SC-INCR in Figure 2, coincide well with the regions where the radiative cooling due to the first-indirect effect of carbonaceous aerosols is reinforced, while the cooling due to both the first-indirect and direct effect of sulfate aerosols is unlikely to account for the regional T2 cooling trends in those regions. The radiative cooling due to the direct effect of carbonaceous aerosols is also reinforced at the above-mentioned regions (Figure 3a) because of the large absorption of incoming solar radiation (SR) by $\mathrm{BC}$ which reduces the SR reaching the surface. $\mathrm{BC}$ also absorbs the upward SR reflecting by the surface or cloud, resulting in a positive RF at the tropopause (Figure 3e). Such absorptions of SR by $\mathrm{BC}$ warm the surrounding air, and then the thermal radiation from the warmed air would warm the surface. Unfortunately, such a warming of surface cannot be precisely estimated from the instantaneous RFs, therefore we cannot state how large is the net impact by the direct effect of carbonaceous aerosols on the change in $\mathrm{T} 2$.

[11] Finally, we formally tested the consistency between the spatio-temporal changes observed for $\mathrm{T} 2$ and the simulated values of $\mathrm{T} 2$ by using a standard optimal fingerprinting method [Allen and Tett, 1999] that was modified to consider the sampling uncertainty introduced by estimating model-simulated spatio-temporal changes from a finite ensemble [Allen and Stott, 2003]. This method is a form of multivariate regression that represents the observations as the sum of the model-simulated spatio-temporal changes multiplied by a scaling factor $(\beta)$, and the internal climate variability. If the value of $\beta$ is positive, the simulated spatiotemporal change is detectable in the observations. Moreover, if $\beta$ is regarded as unity, not only the spatio-temporal pattern, but also the amplitude of the simulated change is consistent with the observations. Note that prior to the calculation of $\beta$, we took decadal means of all data, anomalised them relative to 1940-1979 mean, and projected them onto T4 spherical harmonics. Figure 4 shows the best-estimate values of $\beta$ and their uncertainty range for the spatio-temporal changes between 1940 and 1979 for the three experiments. $\beta$ is only significantly positive for SCINCR with a best-estimate value of about unity, while the values for S-INCR and SC-FIX cannot be statistically distinguished from zero. This implies that the observed spatio-temporal change in $\mathrm{T} 2$ in the mid-20th century that results in a slight global cooling cannot be attributed to any combination of climate forcings in which an increase in carbonaceous aerosols is not included. Furthermore, we regressed the observed spatio-temporal change in $\mathrm{T} 2$ onto the two model-simulated responses from SC-INCR and SINCR to estimate the $\beta$ values for the carbonaceous aerosol forcing alone and the sum of all other forcings by using a linear transformation method [Tett et al., 2002]. The bestestimated values of $\beta$ for carbonaceous aerosol forcing and the sum of all other forcings are $2.19\langle 0.87 \cdot .7 .92\rangle$ and 1.03 $\langle 0.17 \cdot \cdot 3.18\rangle$ respectively, where numbers in \langle\rangle brackets represent the $5-95 \%$ uncertainty range. The uncertainty range of $\beta$ for the carbonaceous aerosol forcing does not include zero; indicating that we can detect the influence of carbonaceous aerosols in the observations in the presence of the other forcings. Moreover, the uncertainty on the amplitude of the carbonaceous aerosol signal includes unity, thus our simulated signal is consistent with the observed response to carbonaceous aerosols in the mid-20th century,

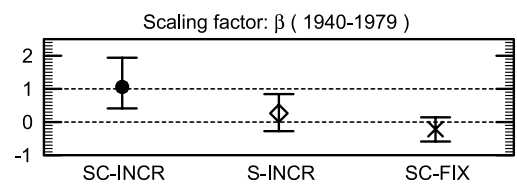

Figure 4. Scaling factors by which we must multiply the model-simulated spatio-temporal change of T2 (19401979) to reproduce the corresponding change in the observation. The error bars show the 5-95\% uncertainty range due to internal variability estimated from the control simulation. 
although the large value of $\beta$ implies that our model possibly underestimates the signal.

\section{Conclusions}

[12] The T2 changes simulated by a climate model are investigated to demonstrate the impact of carbonaceous aerosols on the $\mathrm{T} 2$ trend in the mid-20th century. If we try to take account of the representation of both spatial and temporal trend patterns of $\mathrm{T} 2$, the change in $\mathrm{T} 2$ that occurred in mid-century can only be reproduced adequately when we consider an increase in carbonaceous aerosol emissions. This demonstrates that the radiative cooling due to increased levels of carbonaceous aerosols is an indispensable contributor to the slight cooling in annual global mean T2 in the mid-20th century.

[13] We should note that the cooling trend of T2 in the mid-20th century in the tropical land region that was calculated in SC-INCR could be attributed to an increase in carbonaceous aerosols from biomass burning (not shown). Although the historical emission levels of carbonaceous aerosols from biomass burning is uncertain, we estimated them assuming that its spatial distribution [Cooke and Willson, 1996] in the mid-1980s is unchanged timewise, but that its value is scaled to the historical world population. This assumption is valid to a first-order approximation, because a large part of the biomass burning that occurs in the tropics is relevant to agricultural activities [Crutzen and Andreae, 1990; Hao and Liu, 1994] that are normally traditional and indigenous. This implies that the regions in which biomass burning occurs may not have changed dramatically during the 20th century.

[14] We could not discuss the relative contributions of direct and indirect effects of carbonaceous aerosols, because of a difficulty to estimate the net impact of $\mathrm{BC}$ absorption of solar radiation on the surface temperature. Moreover, large uncertainty in the treatment of indirect effect in the model due to the limited knowledge about aerosol-related atmospheric processes is another difficulty. Although these difficulties should be addressed to advance the present study, the present results clearly show the relative importance of carbonaceous aerosols for the T2 change in the mid-20th century with the use of a climate model and an optimal fingerprinting methodology.

[15] Acknowledgments. The authors thank the K-1 project members for their support and discussion, and two anonymous reviewers for their valuable comments. This work was supported by the Research Revolution 2002 (RR2002) of the Ministry of Education, Culture, Sports, Science and Technology, and by the Global Environment Research Fund (GERF) of the Ministry of the Environment of Japan. The Earth Simulator and a NEC SX-6 at NIES were employed to perform the CGCM simulations. The GFD-DENNOU Library was used for the figures.

\section{References}

Allen, M. R., and P. A. Stott (2003), Estimating signal amplitudes in optimal finger printing, part I: Theory, Clim. Dyn., 21, 477-491, doi:10.1007/s00382-003-0313-9.
Allen, M. R., and S. F. B. Tett (1999), Checking for model consistency in optimal fingerprinting, Clim. Dyn., 15, 419-434.

Andronova, N. G., and M. E. Schlesinger (2000), Causes of global temperature changes during the 19th and 20th centuries, Geophys. Res. Lett., 20, 2137-2140.

Cooke, W. F., and J. J. N. Willson (1996), A global black carbon aerosol model, J. Geophys. Res., 101, 19,395-19,409.

Crutzen, P. J., and M. O. Andreae (1990), Biomass burning in the tropics: Impact on atmospheric chemistry and biogeochemical cycles, Science, $250,1669-1678$.

Delworth, T. L., and T. R. Knutson (2000), Simulation of early 20th century global warming, Science, 287, 2246-2250.

Hao, W. M., and M.-H. Liu (1994), Spatial and temporal distribution of tropical biomass burning, Global Biogeochem. Cycles, 8, 495-503.

Intergovernmental Panel on Climate Change (IPCC) (2001), Climate Change 2001: The Scientific Basis: Contribution of Working Group I to the Third Assessment Report of the Intergovernmental Panel on Climate Change, edited by J. T. Houghton et al., 881 pp., Cambridge Univ. Press, New York.

Jones, P. D., and A. Moberg (2003), Hemispheric and large-scale surface air temperature variations: An extensive revision and an update to 2001, J. Clim., 16, 206-223.

K-1 Model Developers (2004), K-1 coupled GCM (MIROC) description, K-1 Tech. Rep. 1, edited by H. Hasumi and S. Emori, 34 pp., Cent. for Clim. Syst. Res., Univ. of Tokyo, Tokyo.

Lefohn, A. S., J. D. Husar, and R. B. Husar (1999), Estimating historical anthropogenic global sulfur emission patterns for the period 1850-1990, Atmos. Environ., 33, 3435-3444.

Meehl, G. A., W. M. Washington, C. M. Ammann, J. M. Arblaster, T. M. L. Wigley, and C. Tebaldi (2004), Combinations of natural and anthropogenic forcings in 20th century climate, J. Clim., 17, 3721-3727.

Menon, S., J. Hansen, L. Nazarenko, and Y. Luo (2002), Climate effects of black carbon aerosols in China and India, Science, 297, 2250-2253.

Nozawa, T., T. Nagashima, H. Shiogama, and S. A. Crooks (2005), Detecting natural influence on surface air temperature change in the early twentieth century, Geophys. Res. Lett., 32, L20719, doi:10.1029/ 2005GL023540.

Ramanathan, V., P. J. Crutzen, J. T. Kiehl, and D. Rosenfeld (2001), Aerosols, climate, and the hydrological cycle, Science, 294, 2119-2124.

Ramanathan, V., C. Chung, D. Kim, T. Bettge, L. Buja, J. T. Kiehl, W. M. Washington, Q. Fu, D. R. Sikka, and M. Wild (2005), Atmospheric brown clouds: Impacts on South Asian climate and hydrological cycle, Proc. Natl. Acad. Sci. U. S. A., 102, 5326-5333.

Takemura, T., T. Nakajima, O. Dubovik, B. N. Holben, and S. Kinne (2002), Single-scattering albedo and radiative forcing of various aerosol species with a global three-dimensional model, J. Clim., 15, 333-352.

Takemura, T., T. Nozawa, S. Emori, T. Y. Nakajima, and T. Nakajima (2005), Simulation of climate response to aerosol direct and indirect effects with aerosol transport-radiation model, J. Geophys. Res., 110, D02202, doi:10.1029/2004JD005029.

Tett, S. F. B., J. F. B. Mitchell, D. E. Parker, and M. R. Allen (1996), Human influence on the atmospheric vertical temperature structure: Detection and observation, Science, 274, 1170-1173.

Tett, S. F. B., P. A. Stott, M. R. Allen, W. J. Ingram, and J. F. B. Mitchell (1999), Causes of twentieth-century temperature change near the Earth's surface, Nature, 399, 569-572.

Tett, S. F. B., et al. (2002), Estimation of natural and anthropogenic contributions to twentieth century temperature change, J. Geophys. Res., 107(D16), 4306, doi:10.1029/2000JD000028.

Wigley, T. M. L., P. D. Jones, and S. C. B. Raper (1997), The observed global warming record: What does it tell us?, Proc. Natl. Acad. Sci. U. S. A., 94, 8314-8320.

S. A. Crooks, Department of Physics, University of Oxford, Clarendon Laboratory, Parks Road, Oxford OX1 3PU, UK.

T. Nagashima, T. Nozawa, H. Shiogama, and T. Yokohata, National Institute for Environmental Studies, Atmospheric Environment Division, Ibaraki 305-8506 Japan. (nagashima.tatsuya@nies.go.jp)

T. Takemura, Research Institute for Applied Mechanics, Kyushu University, Fukuoka 816-8580, Japan. 